Article

\title{
Gold Price Modeling Using System Dynamics
}

\author{
Wipawee Tharmmaphornphilas*, Haruetai Lohasiriwat, and Pathompol Vannasetta \\ Department of Industrial Engineering, Faculty of Engineering, Chulalongkorn University, Bangkok 10330, \\ Thailand \\ *E-mail: wipawee.t@eng.chula.ac.th
}

\begin{abstract}
The global gold market has recently attracted a lot of attention and the price of gold is relatively higher than its historical trend. This paper constitutes the first exercise of system dynamics applied to predict gold price in monthly frequency from January 2010 to June 2011. Rather than static forecasting characteristics found in another quantitative method, time-series, system dynamics allows possibility for prediction based on capturing causal interactions and consequently the feedback loops usually found in a complex system behaviour such as the gold price system. Therefore, it was expected that moving toward forecasting method utilizing system dynamics model could result in better prediction of the gold price. Our paper supports such hypothesis. Having ability to take into account of qualitative factors particularly political chaos and economic crisis events, the model developed in this paper reduces the prediction error, mean absolute percent error (MAPE), to merely $2 \%$ compared to approximately $9 \%$ error found with Holt-Winter Exponential Smoothing and $11 \%$ error using Box-Jenkins Method.
\end{abstract}

Keywords: System dynamics model, gold price, forecasting.

ENGINEERING JOURNAL Volume 16 Issue 5

Received 20 March 2012

Accepted 20 May 2012

Published 1 October 2012

Online at http://www.engj.org/

DOI:10.4186/ej.2012.16.5.57 


\section{Introduction}

For many reasons, gold has been used in various sectors (e.g., jewellery, electronics, computers, medical, and aerospace). Governments use gold as a relative standard for currency equivalents. Investors hold gold reserves as a hedge against inflation, or currency devaluation and also to diverse their portfolio for managing risk purpose. Some manufacturers require the use of gold for its special qualification when other less expensive substitutes cannot be identified. It is not surprising if there will be growing demand in gold usage in the future. Today, like most commodities, the price of gold is driven by supply and demand as well as speculation. Due to limitation in the gold supply amount, its historical trend reveals continually raising in price. The price actually increases significantly since the beginning of 2009. Forecasting of gold price has been interested for long. This paper applies the system dynamics approach to study the behavior of the gold price movement. In system dynamics, a system is represented by a closed-loop structure which models the relationship and feedback among system factors [1] [2] [3]. A problem or a system (e.g., political system, mechanical system, or gold price system) is first represented as a stock and flow diagram. Stock shows the quantity of study factor while flows demonstrate factors which come in and out to change the stock level. For example, the stock and flow diagram of money in bank account may look like illustration in Fig. 1. "Stock" is the steady quantity of money in bank account and "Flow" is the money which comes in and out in the account. The inflow is the steady income including the interest payments and outflow is the spending. In addition, the positive (+) and negative (-) symbols shown with interaction arrows are used to define whether the relationship between variables at the two ends is in direct or inverse direction [4]. For instance, the interest rate and the interest payments will have a link with positive sign. Another important part in the system dynamics is feedback. A change of bank account balance will have feedback to interest payments and spending in the same direction, and hence positive signs are shown in the feedback arrow [5].

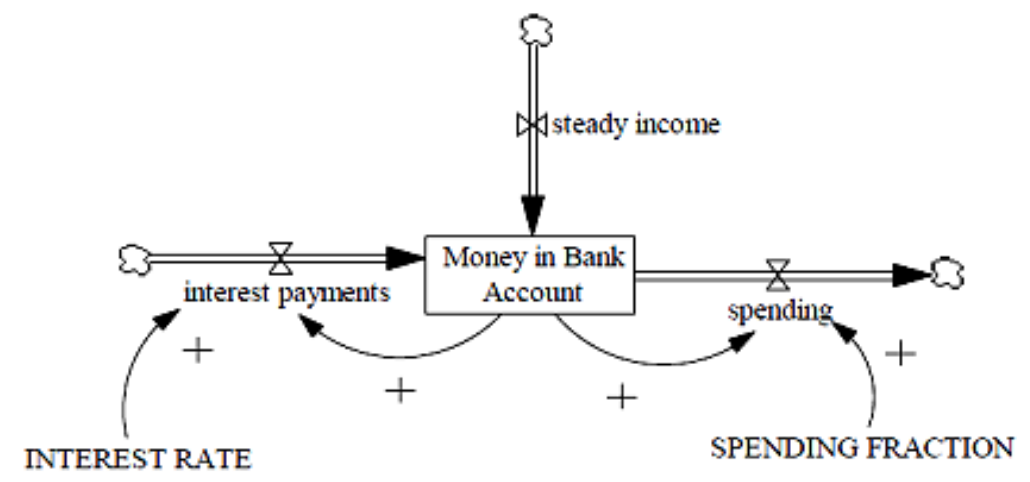

Fig. 1. System dynamics of money in bank account [5].

After developing the diagram, we can visualize a simple map of the studied system with all its constituent components and their interactions. This defined structure aids in analyzing process qualitatively. However, to be able to perform quantitative analysis, mathematical relationships will need to be developed to connect all factors in the structure. Only after this, then we can possibly ascertain the system's behavior if there are any changes in system components quantitatively. For example, if the interest rate is changed, the interest payments is also changed which causes the money in the bank account to get higher or lower. The equation that we use to calculate the interest payment is multiplication of the bank account balance and the interest rate (interest payment $=$ money in bank account $\mathrm{x}$ interest rate). This paper uses the linear regression analysis to form a relationship function among all factor relationships. By capturing interactions and consequently the feedback loops, our model enhances the understanding of the overall gold price system structure. It make possible for forecasting gold price by taking into account of all factor interactions and feedbacks at the same time. Having such ability is highly useful in gold investing market where making decision in the early process is considered an advantage. Also, the gold price inflation can be foreseen too.

The subsequent sections of this paper describe all processes of our model development. Following typical system dynamics methodology, our method starts out from model conceptualization to illustrate all influenced factors to the gold price. Extensive literature reviews in corporate with interviewing practitioners in gold market around the country are two major sources in identifying all factors at the first phase. Then, 
we formulate mathematical relationships among the predefined factors using regression analysis by gathering the average monthly data available to public. The total of fifteen linear relationships was set up. Due to system dynamics model, when there is any change for a variable, all other related factors will automatically get affected. The calculated results are the model predicted values for those variables in next time period which feedback behaviour is included in the proposed model. Eventually, our proposed model was evaluated to compare its effectiveness against other forecasting methods. Some limitations of the model and suggested future studies for model improvement are discussed in the final section.

\section{Model Conceptualization}

The objective of our forecasting model, gold price, is first set as a stock in the stock and flow diagram. The accumulation and reduction of gold price stock is a result of two major flows; rate of increasing price as the inflow and rate of decreasing price as the outflow. Six contributed factors to both flows are defined (see Fig. 2) via literature review in economics subject and interviewing with Thai practitioners in gold market.

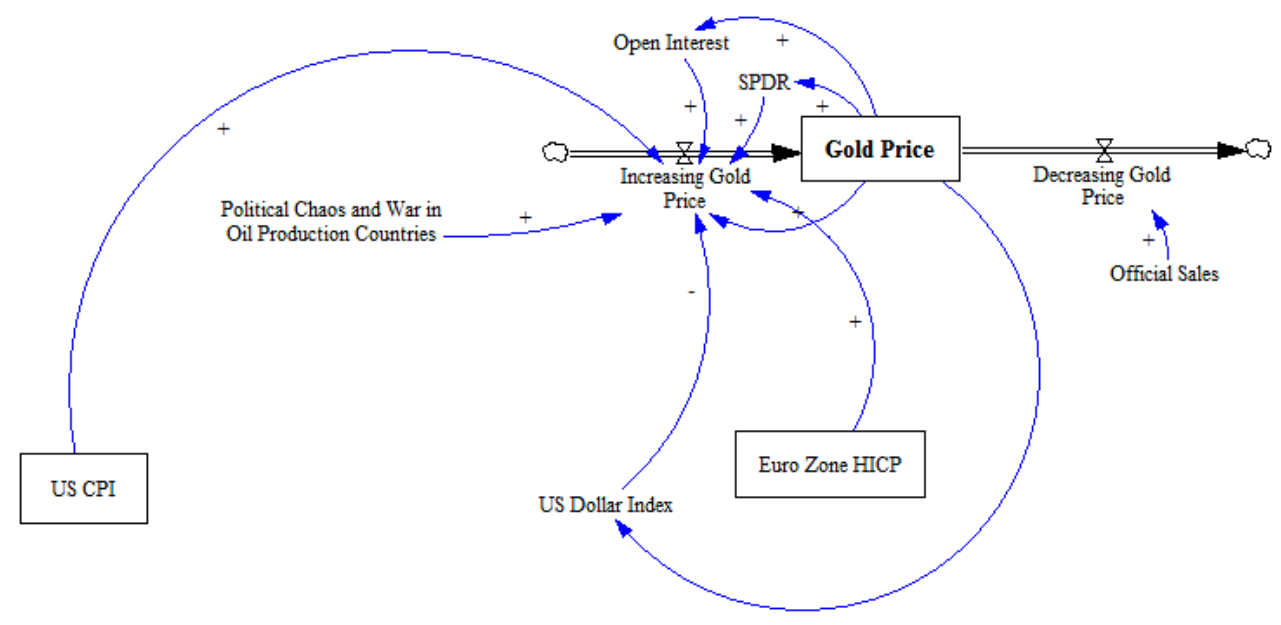

Fig. 2. Factors affecting the gold price.

Figure 2 demonstrates all six major factors that affect inflow and outflow of gold price stock. The first five factors are the reinforced ones which increase gold price. (1) Consumer Price Index (CPI), the index used to measure inflation rate calculated from percent change in the overall goods and services price between two different time periods. Generally, the price index measures the level change in prices of goods and services. Since gold is known to have its own stores of value [6] and holding no market risk [7], therefore higher inflation rate generally instigate investments in gold as a hedge against the inflation. Although not moving in the same pace, gold prices have tended to track the CPI meaning both variables hold positive relationship. Both U.S. CPI and Euro Zone HICP are used in the present model as they are major currencies in the world gold market. (2) SPDR (Standard \& Poor's Depositary Receipts) gold shares, the international level gold trust service who mainly invests in gold bar. SPDR is the world biggest gold investors, and thus the buying action of SPDR gold shares directly means increasing in the gold demand and therefore, increasing of gold price as a result. At the same time, when gold price increases, more investors will jump into the market and further increase SPDR buying amount. As a result, there are connections between SPDR to both increasing gold price flow and gold price stock with positive relationships. (3) Open interest, similar to the previous factor, the more amount of open interest means higher gold demand. Thus, this factor hold positive relationships in the same manner modelled with SPDR. (4) Political chaos and war in oil production countries, by holding consistent positive trends between the crude oil price and the gold price, this last reinforced factor is later added to the model. Normally, whenever there are such events occurring or even just speculation, a bunch of investors ranging from individuals to organizations will diversify their collections in portfolios to invest more in gold. Expectantly that broaden out their assets will protect against the risk of single or class of securities. Thus, the occurring of such events is expected to result in increasing of gold price. On the other hand, balanced factor for rising 
gold price or the one negatively relating to increasing of gold price is (5) U.S. Dollar Index, the performance measure of U.S. Dollar against a basket of currencies. Because the world gold market now seems to be dominated by U.S. dollar bloc, appreciations or depreciations of that dollar usually effects on the price of gold. The dollar depreciation results in increasing gold price due to the fact that investor wants to lower their risk on exchange rate. Then, the only main factor for outflows or decreasing of gold price is (6) Official Sales from various countries and organizations around the world. Whenever, some world's largest gold holders announce official gold sales, it will negatively impact demand in gold market and finally reduce the market price. At this point we have come up with the system dynamic model for gold price and its related major factors as shown in Fig. 2. However, because consumer price indexes, both the U.S. and Euro zone ones, are highly affected from fluctuation of crude oil price, we then have to extend our model in more detail on the underlying factors associate with such indexes particularly the oil price. Added oil price modelling is illustrated in Fig. 3.

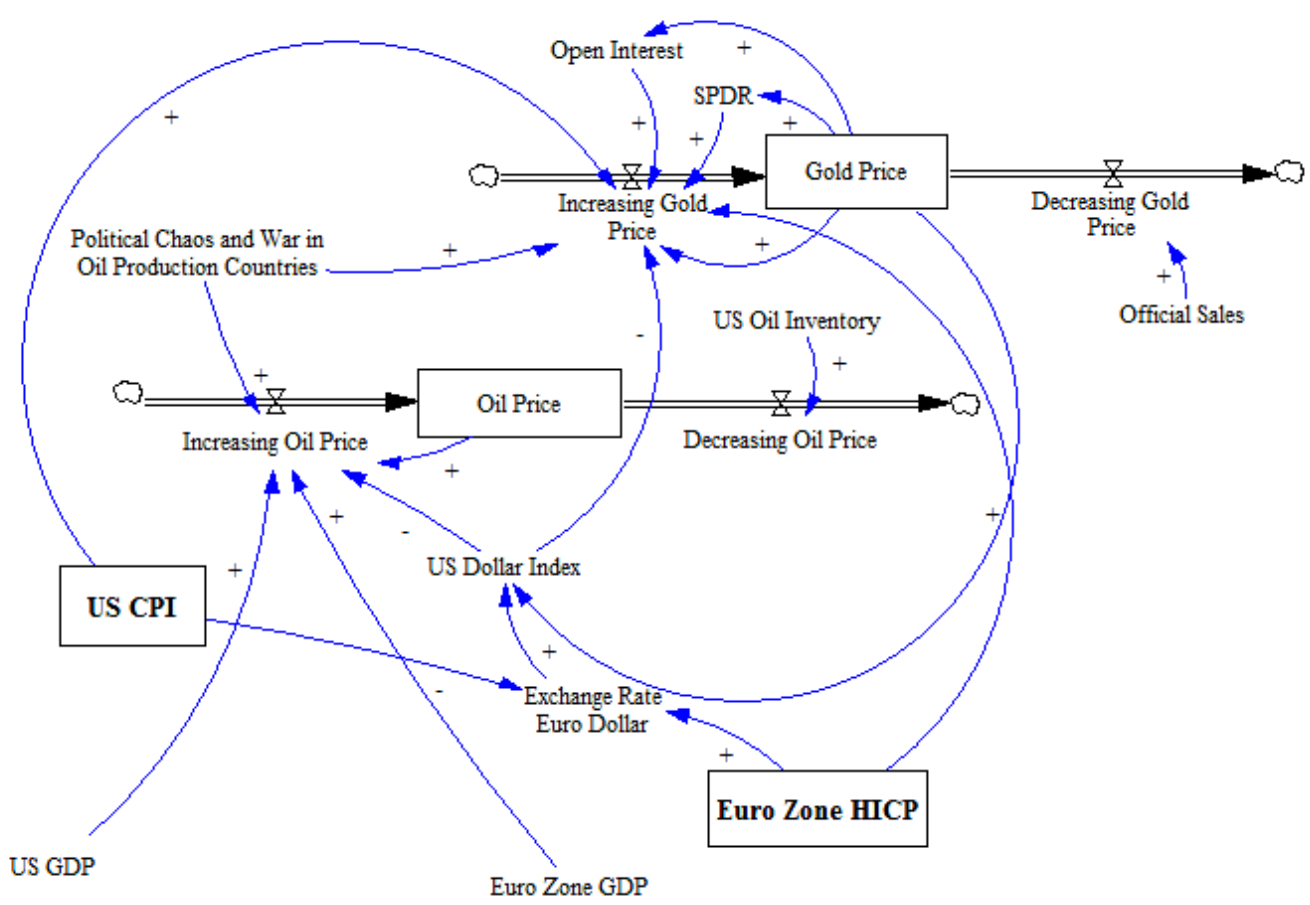

Fig. 3. Factors affecting the oil price and the gold price.

Readers interested in elaboration process of oil price modelling are recommended to refer to the author's previous publication [8]. In summary, two out of six factors from gold price model are found to have impact on the oil price (i.e., U.S. Dollar Index and Chaos/War Factor). Like gold price model, U.S. Dollar Index ties to oil price negatively. When the dollar falls, oil prices rise because investors are more likely to transfer their investments toward more on oil (and gold as described earlier). In terms of chaos factor, whenever there is war or political issues in oil production countries, it means there will be limitation or tension of oil supply. Thus the oil price will be increasing as a consequent. Such circumstances have been evidenced for long through many world crisis periods such as the Suez Crisis in 1956, the Arab-Israel War in 1973, the Iranian Revolution (Islamic Revolution) in 1978 and the Persian Gulf War in 1990 [9].

Nonetheless, rather than having investor demands factors (i.e., Open Interest and SPDR) play roles in gold price, the oil price is in fact affected by the actual consumption demands much shown by the Gross Domestic Product or GDP. Therefore, two additional factors are integrated in the model including (7) U.S. GDP and (8) Euro Zone GDP. Growing in economics results in higher oil consumption and eventually leads to increasing in oil price. This effect is shown with positive relationships between the GDPs and increasing in oil price. To decrease oil price, the only factor control such event is (9) the U.S. Oil Inventory. When the crude oil inventory decreases from the previous level, the market will recognize the tension of supply. Then, the oil price will be higher [10]. Hence, oil inventory factor holds positive relationship toward decreasing oil price outflow. Note that at this point, we also add another factor, (10) the Exchange Rate 
Euro Dollar. Because the euro makes up most of the U.S. Dollar Index, a change in Euro will eventually affect the U.S. dollar index. Specifically speaking, increasing in exchange rate (e.g., 1.4 Euro/\$US to be 1.6 Euro/\$US) means increasing in U.S. Dollar Index therefore positive relationship is assigned between Euro exchange rate and U.S. Dollar Index.

Then, there is also the relationship between the inflation rate and the exchange rate. Using the Absolute Purchasing Power Parity Theory, which states that a bundle of goods should cost the same in any country once the exchange rate is taken into account. The law of one price between these two currencies can be expressed mathematically as shown in Eq. (1).

$$
\text { Exchange Rate Euro Dollar }=\frac{\text { Euro Customer Price Index (Euro Zone HICP) }}{\text { US Customer Price Index (US CPI) }}
$$

The formula above clearly explains two relationships in our model; the positive correlation between exchange rate and Euro Zone HICP as well as the negative correlation between exchange rate and US CPI.

At this instant, our system dynamic model elaborates casual relationships among all major variables influencing gold and oil prices as well as the relationship between them. The only economic variable included at present is the Customer Price Index (CPI). Having its own fluctuation, it is thus necessary to detail more regarding underlying factors controlling the CPI to come up with the better forecasting model. As a measure of inflation, any factors influencing inflation are incorporated in to our model at this stage as variables affect the CPIs, both US and Euro Zone CPI. Inflation is basically the change in the level of prices over time. Two main causes of inflation are Demand-Pull and Cost-Push Inflation. Demand-pull inflation occurs when there is an increase in aggregate demand due to economic growth. In the other words, there is positive relationship exists between the GDP and the increasing of CPI. Then, we further our model to include variables utilized in GDP calculation. A common used method for GDP computation is the expenditure approach, which involves counting expenditures on goods and services by different groups in the economy such as (11) personal consumption expenditures $(C),(12)$ gross private domestic investment (I), (13) government consumption expenditures and gross investment (G), (14) exports of goods and services $(\mathrm{X})$ and $(15)$ imports of goods and services $(\mathrm{M})$. In the expenditure approach, GDP is expressed in term of the above variables using Eq. (2).

$$
\mathrm{GDP}=\mathrm{C}+\mathrm{I}+\mathrm{G}+\mathrm{X}-\mathrm{M}
$$

Note that the term X-M is commonly known as trade balance or net exports. On the other hand, costpush inflation occurs when production costs of goods and services increase due to another additional factor, the rising of (16) labour cost incorporate with the already mentioned variable, the increasing of oil price [11]. All these inflation variables and their effects on gold price system are included. The final system dynamic model used in our forecasting method is shown in Fig. 4. 


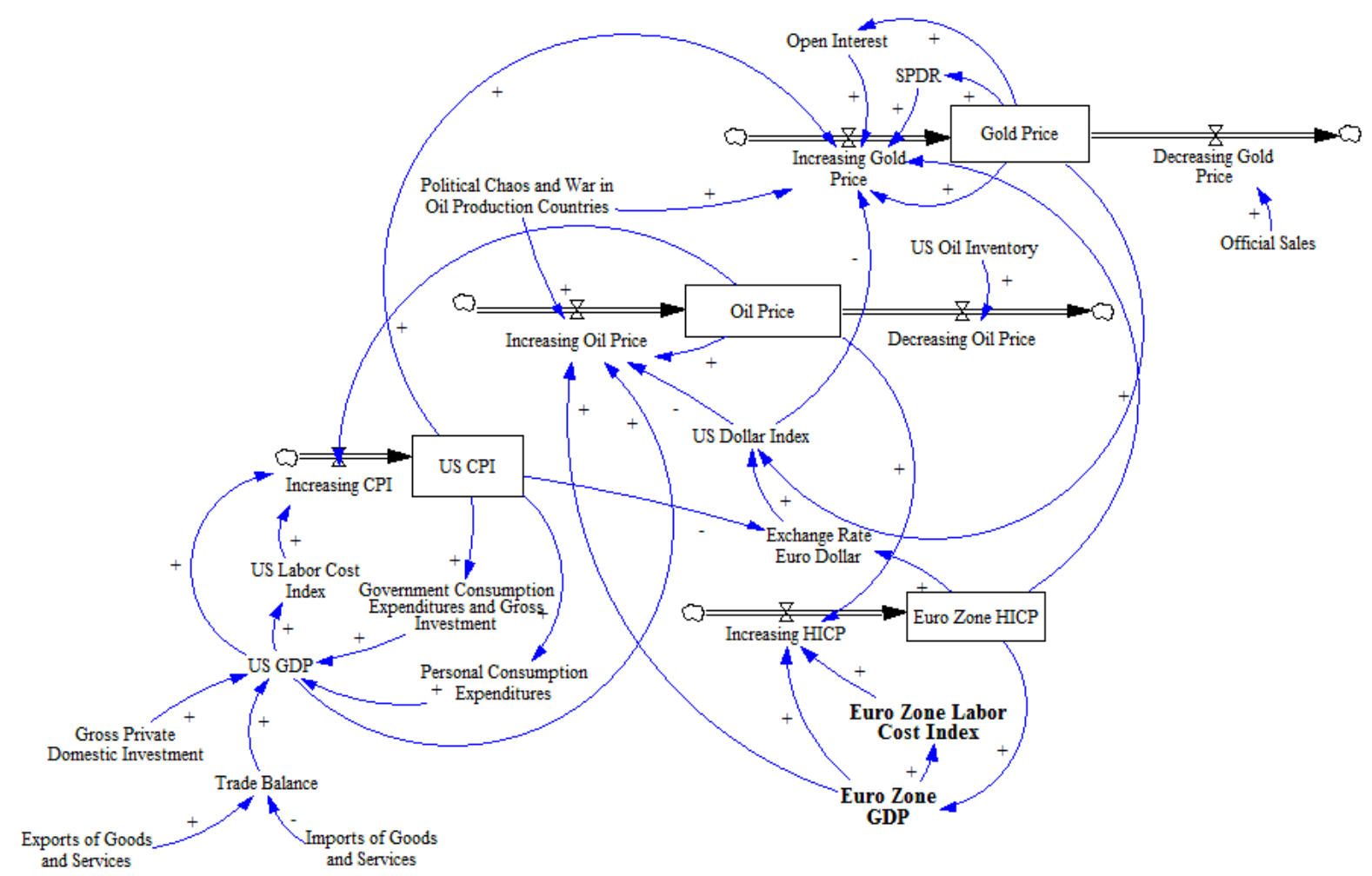

Fig. 4. System dynamic model for the gold price.

\section{Mathematical Model Formulation}

\subsection{Quantitative Data}

At this phase, it is necessary to identify all relationships shown in Fig. 4 mathematically in order to utilize the model for forecasting purpose. To perform this, we apply linear regression using least squares method. Historical data available to public are gathered from various data sources as listed in Table 1 . Note that we used monthly historical data staring from year 2002 until 2009 to derive all relationships.

Table 1. Model variables and source of analysis data.

\begin{tabular}{|c|c|}
\hline Factor & Data Source \\
\hline Gold price & World Gold Council \\
\hline US CPI & U.S. Department of Labor: Bureau of Labor Statistics \\
\hline Euro Zone HICP & Eurostat \\
\hline SPDR & SPDR Gold Shares \\
\hline Open Interest & U.S. Commodity Futures Trading Commissions \\
\hline US Dollar Index & Board of Governors of the Federal Reserve System \\
\hline Rate Euro/Dollar & Board of Governors of the Federal Reserve System \\
\hline Official Sales & World Gold Council \\
\hline Oil price & $\begin{array}{r}\text { U.S. Department of Energy: Energy Information } \\
\text { Administration and Organization of the Petroleum Exporting } \\
\text { Countries }\end{array}$ \\
\hline US Oil Inventory & $\begin{array}{r}\text { U.S. Department of Energy: Energy Information } \\
\text { Administration }\end{array}$ \\
\hline US GDP & U.S. Department of Commerce: Bureau of Economic Analysis \\
\hline U.S. Labor Cost Index & U.S. Department of Labor: Bureau of Labor Statistics \\
\hline Personal Consumption & U.S. Department of Commerce: Bureau of Economic Analysis \\
\hline Gross Private Domestic Investment (I) & U.S. Department of Commerce: Bureau of Economic Analysis \\
\hline
\end{tabular}


Government Consumption

Expenditures and Gross Investment $(G)$

Exports of Goods and Services (X)

Imports of Goods and Services (M)

Euro Zone GDP

Euro Zone Labor Cost Index
U.S. Department of Commerce: Bureau of Economic Analysis

U.S. Department of Commerce: Bureau of Economic Analysis

U.S. Department of Commerce: Bureau of Economic Analysis

Eurostat

Eurostat

For example, the program run result for the relationship between Gold Price as a dependent variable and five independent variables (i.e., average of US CPI and Euro Zone HICP, SPDR, Open Interest, US Dollar Index, and Official Sales) is shown in Table 2.

Table 2. Linear regression analysis of the gold price model.

\begin{tabular}{lcccr}
\hline Variables & Coefficient & Std. Error & t-Statistic & Prob. \\
\hline Average of US CPIT and HICP & 8.748574 & 3.387763 & 2.582404 & 0.0114 \\
SPDR & 0.343993 & 0.038711 & 8.886201 & 0.0000 \\
Open Interest & 0.000553 & 0.000106 & 5.237493 & 0.0000 \\
Official Sales & -0.238669 & 0.094639 & -2.521895 & 0.0134 \\
US Dollar Index & -0.107253 & 1.240781 & -0.086440 & 0.9313 \\
Regression Constant & -565.0707 & 417.2946 & -1.354129 & 0.1791 \\
\hline R-sqaured & 0.970449 & Mean dependent var & 584.1458 \\
R-squared adjusted & 0.968807 & S.D. dependent var & 234.9435 \\
S.E. of regression & 41.49451 & Akaike info criterion & 10.34946 \\
Sum squared residual & 154961.5 & Schwarz criterion & 10.50973 \\
Log likelihood & -490.7741 & F-statistic & 591.1146 \\
Durbin-Watson stat & 0.363068 & Prob (F-statistic) & 0.000000 \\
\hline
\end{tabular}

Thus, equation used to predict gold price in our model is shown in Eq. (3). Note that this equation is used only under no chaos factor.

$$
\begin{aligned}
& \text { Gold Price } \left._{\mathrm{t}}=9 \text { (average of US CPI }_{\mathrm{t}-1} \text { and HICP } \mathrm{t}_{\mathrm{t}-1}\right)+0.35 \text { SPDR }_{\mathrm{t}-1}+0.00055 \\
& \text { Open Interest } t_{-1}-0.239 \text { Official Sales } t-1-0.107 \text { US Dollar Index t-1 }-565
\end{aligned}
$$

Utilizing similar methods repeatedly, we are able to describe all related regression relationships. These derived relationships sufficiently connect fifteen variables shown in the model whereas the qualitative factor (i.e., political chaos and war factor) will require different process discussed in the following section.

\subsection{Qualitative Data}

Because there is also qualitative variable in our model, transformation of this data into quantitative value is necessary. Through extensive reviewing of gold price and oil price historical data, we found that whenever there is economic crisis, the prices would soar up over our forecasting speculation. Average of $4 \%$ up for the gold price and 5\% up for the oil price are found. Therefore, to quantify the effect of this variable, we have set up additional parameter to both gold and oil price formulas. This added parameter is calculating from percentage of price change multiplied by the price from its previous time period. Then, another regression analysis was performed to eventually gain Eq. (4) used to predict gold price under situation when there is chaos factor. In terms of inputting data for our dynamic model, the chaos variable holds default setting at " 0 " meaning that there is no political chaos or war in oil production countries. However, when it occurs, manually alters the variable input to be " 1 " is needed to trigger additional adjustment to eventually heighten up the gold price.

$$
\begin{aligned}
\text { Gold Price }_{\mathrm{t}}= & \left.3.95 \text { (average of US CPI } \mathrm{t}_{\mathrm{t}-1} \text { and HICP } \mathrm{t}_{\mathrm{t}-1}\right)+0.17 \text { SPDR }_{\mathrm{t}-1}+0.00034 \\
& \text { Open Interest } \mathrm{t}_{\mathrm{t}-1}-0.0823 \text { Official Sales }_{\mathrm{t}-1-2.28 \text { US Dollar Index }_{\mathrm{t}-1}} \\
& -107.5+15.2(0.04)\left(\text { Chaos Factor }_{\mathrm{t}-1}\right)\left(\text { Gold Price }_{\mathrm{t}-1}\right)
\end{aligned}
$$


Additionally, because the chaos and war factor is also expected to affect oil price, our model thus includes two separate equations used in the prediction of oil price under with and without chaos situation.

\subsection{Example of Gold Price Prediction using System Dynamics Model}

As mentioned in the earlier section, our model predicts gold price utilizing interactions among predefined variables. Basically, values from the prior time period will feedback and being inputs for predicting the other variables in the subsequent time. Also, there are variables which are not calculated results of the regression equations but rather being added into model under appropriate time. These variables include chaos factor and official sales.

For example, to predict gold price for January $2010\left(t_{1}\right)$, our model requires inputs including some actual values from December 2009 ( $\left.\mathrm{t}_{0}\right)$ (i.e., those in steps 1-5) and calculation results from regression equations (i.e., those in steps 6-9) as shown in Table 3.

Table 3. Variable values for gold price prediction $\left(\mathrm{t}_{0}\right)$.

\begin{tabular}{lccr}
\hline Step & Factors & Values & Status / Regression Equation \\
\hline 1 & Gold Price $\left(\mathrm{t}_{0}\right)$ & $1,087.50$ & Initial Value \\
2 & US CPI $\left(\mathrm{t}_{0}\right)$ & 110.56 & Initial Value \\
3 & Euro Zone HICP $\left(\mathrm{t}_{0}\right)$ & 108.91 & Initial Value \\
4 & Chaos Factor $\left(\mathrm{t}_{0}\right)$ & 0 & Constant \\
5 & Official Sales $\left(\mathrm{t}_{0}\right)$ & 0 & Constant \\
6 & SPDR $\left(\mathrm{t}_{0}\right)$ & $1,112.59$ & 1.5 Gold Price $\left(\mathrm{t}_{0}\right)-518.66$ \\
7 & Open Interest $\left(\mathrm{t}_{0}\right)$ & 496,208 & 363 Gold Price $\left(\mathrm{t}_{0}\right)+101445$ \\
8 & Exchange Rate Euro/Dollar $\left(\mathrm{t}_{0}\right)$ & 0.734 & 5.74 (Euro Zone HICP $\left(\mathrm{t}_{0}\right) /$ US CPI $\left.\left(\mathrm{t}_{0}\right)\right)-4.92$ \\
9 & US Dollar Index $\left(\mathrm{t}_{0}\right)$ & 77.19 & 82.2001 Exchange Rate Euro Dollar $\left(\mathrm{t}_{0}\right)$ \\
& & & -0.002 Gold Price $\left(\mathrm{t}_{0}\right)+19$ \\
\hline
\end{tabular}

Then, gold price $\left(\mathrm{t}_{1}\right)$ is calculated by inputting all values shown in Table 3 into Eq. (3)

$$
\begin{aligned}
\text { Gold Price }\left(\mathrm{t}_{1}\right)= & 9(110.56+108.91) / 2+0.35(1,112.59)+0.00055(496,208)-0.239(0) \\
& -0.107(77.19)-565 \\
= & 1,076.68
\end{aligned}
$$

Once the model acquires this calculated gold price $\left(\mathrm{t}_{1}\right)$, all other variables in which gold price is an

\begin{tabular}{|c|c|c|c|}
\hline Step & Factors & Values & Status / Regression Equation \\
\hline 1 & Gold Price $\left(\mathrm{t}_{1}\right)$ & $1,076.68$ & Described above \\
\hline 2 & US CPI $\left(t_{1}\right)$ & 111.60 & $\begin{array}{l}2.7 \times 10^{-12} \text { US GDP }\left(\mathrm{t}_{0}\right)+0.52 \text { US Labor Cost } \\
\text { Index }\left(\mathrm{t}_{0}\right)+0.03 \text { Oil Price }\left(\mathrm{t}_{0}\right)+12 \\
2.8 \times 10^{-13} \text { Euro Zone GDP }\left(\mathrm{t}_{0}\right)+0.68 \text { Euro }\end{array}$ \\
\hline 3 & Euro Zone HICP $\left(\mathrm{t}_{1}\right)$ & 108.27 & $\begin{array}{r}\text { Zone Labor Cost Index }\left(\mathrm{t}_{0}\right)+0.032 \text { Oil Price } \\
\left(\mathrm{t}_{0}\right)+33\end{array}$ \\
\hline 4 & Chaos Factor $\left(\mathrm{t}_{1}\right)$ & 0 & Constant \\
\hline 5 & Official Sales $\left(\mathrm{t}_{1}\right)$ & 0 & Constant \\
\hline 6 & $\operatorname{SPDR}\left(\mathrm{t}_{1}\right)$ & $1,096.35$ & 1.5 Gold Price $\left(\mathrm{t}_{1}\right)-518.66$ \\
\hline 7 & Open Interest $\left(t_{1}\right)$ & 492,279 & 363 Gold Price $\left(t_{1}\right)+101445$ \\
\hline 8 & Exchange Rate Euro/Dollar ( $\left.\mathrm{t}_{1}\right)$ & 0.65 & 5.74 (Euro Zone HICP $\left(\mathrm{t}_{1}\right) /$ US CPI $\left.\left(\mathrm{t}_{1}\right)\right)-4.92$ \\
\hline 9 & US Dollar Index $\left(\mathrm{t}_{1}\right)$ & 70.16 & $\begin{array}{r}\text { 82.2001 Exchange Rate Euro/Dollar }\left(\mathrm{t}_{1}\right) \\
-0.002 \text { Gold Price }\left(\mathrm{t}_{1}\right)+19\end{array}$ \\
\hline
\end{tabular}
independent variable will further calculated. Example results for $\mathrm{t} 1$ are shown in Table 4.

Table 4. Variable values for gold price prediction $\left(\mathrm{t}_{1}\right)$. 
Note that in order to acquire values for independent variables related with US CPI and Euro Zone HICP, some other initial inputs are required at period $t_{0}$.

\section{Model Evaluation}

For evaluation purpose, we inputted initial value for all variables using actual available data of December 2009 (i.e., gold price, oil price, US CPI, Euro zone HICP, gross private domestic investment, exports and imports of goods) except the official sales and US oil inventory which manually input are required monthly. Then, the model will forecast gold price from January 2010 until the predefined end time. Note that we use Vensim system dynamic program as the tool for calculating all interaction effects defined earlier. Our basic assumption is that the model can forecast gold price until there is change in the qualitative variable or economic chaos factor. Therefore, as in year 2010, the first chaos happened around the end of February when there was a massive earthquake in Chile and Curacao and the productions of two oil refineries were halted due to the damages, the first estimation of year 2010 is run through only January and February. Then, to estimate price in March 2010 onward, we need to manually input the actual February data and change the Political chaos or war variable to " 1 " to illustrate that the event occurs so that the system will determine the $4 \%$ and $5 \%$ of growing up gold and oil price respectively. We hold these initial values and predict gold price from March 2010 until June 2010. Later, in June and July 2010, there was an excess oil supply that made the oil price lower than the predicted value. So another adjustment was made, by using actual data in June 2010 as initial input and switching "Political chaos or war in oil production countries" to be "0" and this setting can estimate the following two months until flooding problem happened in Pakistan during August 2010. Thus, another adjusting was made by using actual August 2010 data as the inputs combined with value "1" of chaos factor, here we can estimate gold price from September until December 2010. Note that various chaos factors actually happen along this time period, starting from an insurrection in France in September and October. Petrol shortages were spreading across the country as all 12 oil refineries had joined a continuous strike. Some 2,700 of France's 12,600 petrol stations had completely run out of supplies. Also, there was crisis in Tunisia along this time. These chaos has relief around December 2010, thus we have again put December data and switch "0" to estimate January and February 2011 gold prices. Lastly, starting from the end of February 2011 until June 2011, there was agitation in Egypt and Libya, thus initial data of February 2011 was used and chaos factor is set at "1" to estimate gold price until June 2011. Following data input methodology discussed in this section, Fig. 5 compares the actual gold price data from January 2010 to June 2011 with the expected (forecast) counterparts.

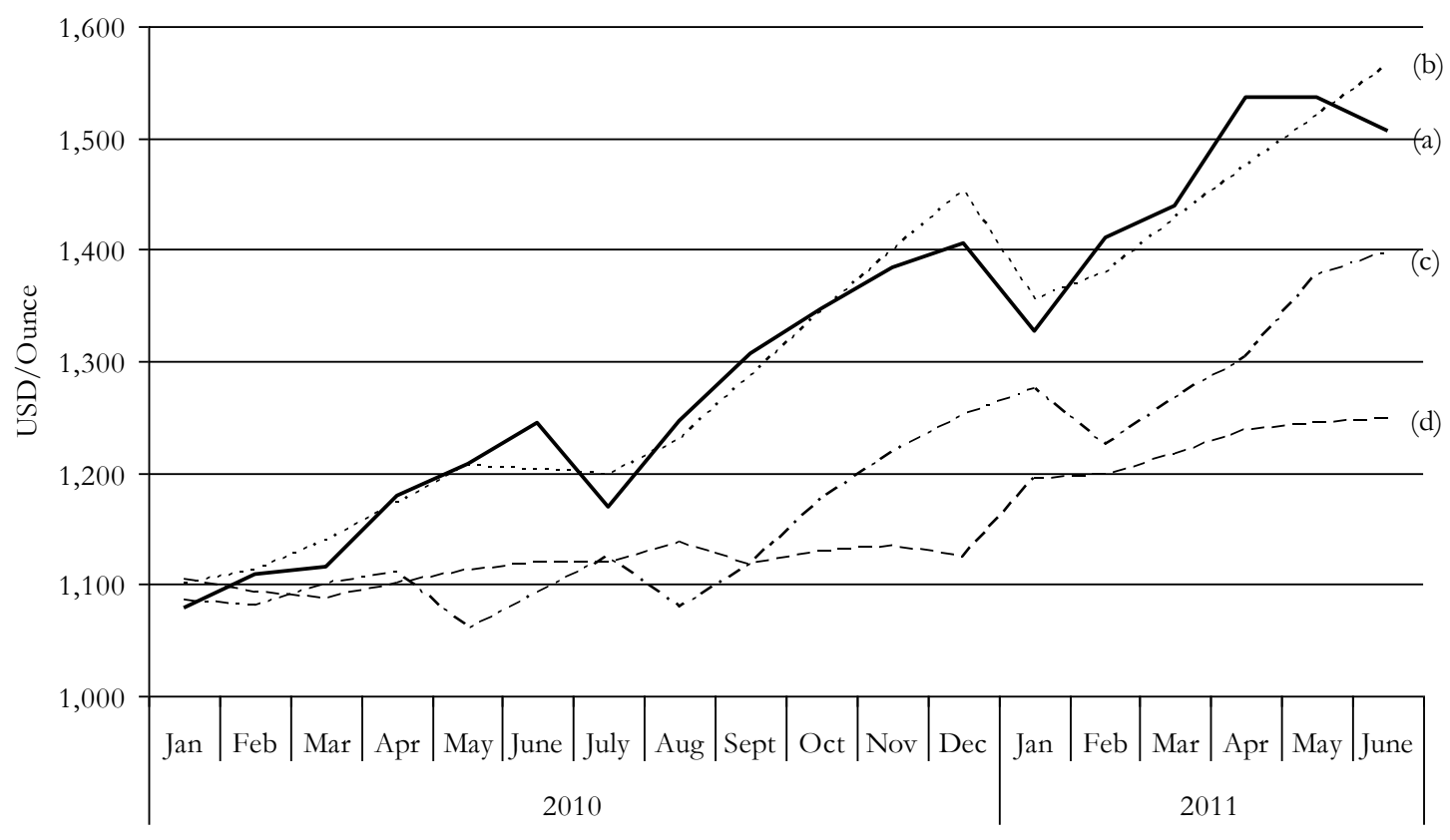

Fig. 5. Comparison of (a) actual gold price data and the forecast gold price data using (b) system dynamics, (c) holt-winter exponential smoothing, and (d) box-jenkins. 
Our system dynamic model developed in this paper can forecast gold price with the average of $2 \%$ mean absolute percent error (MAPE). This prediction error is much lower than approximately $9 \%$ error found with Holt-Winter Exponential Smoothing and 11\% error using Box-Jenkins Method. Approaches and formulas used in the later two methods are described in [12] and [13] respectively. Major underlying reasons for better prediction is expected to be the result of having ability to take into account of qualitative factors particularly political chaos and economic crisis events into system dynamic forecasting model. At the same time, system dynamic scheme allows possibility for incorporation of interaction and feedback effects among all related variables rather than relying solely on historical data as found in Time series. Table 3 shows the monthly percentage error from our model calculation.

Table 5. Results of monthly percentage of error.

\begin{tabular}{lccr}
\hline Month, Year & \multicolumn{2}{c}{ Gold (US Dollar/Ounce.) } & $\begin{array}{r}\text { Mean Absolute Percent } \\
\text { Error (MAPE, \%) }\end{array}$ \\
\hline January, 2010 & $1,078.50$ & $1,101.38$ & 2.12 \\
February, 2010 & $1,108.25$ & $1,112.47$ & 0.38 \\
March, 2010 & $1,115.50$ & 1139.60 & 2.16 \\
April, 2010 & $1,179.25$ & 1172.15 & 0.60 \\
May, 2010 & $1,207.50$ & 1205.53 & 0.16 \\
June, 2010 & $1,244.00$ & $1,202.14$ & 3.36 \\
July, 2010 & $1,169.00$ & $1,197.96$ & 2.48 \\
August, 2010 & $1,246.00$ & 1228.95 & 1.37 \\
September, 2010 & $1,307.00$ & 1286.62 & 1.56 \\
October, 2010 & $1,346.75$ & 1342.97 & 0.28 \\
November, 2010 & $1,383.50$ & 1398.24 & 1.07 \\
December, 2010 & $1,405.50$ & 1452.59 & 3.35 \\
January, 2011 & $1,327.00$ & $1,354.83$ & 2.10 \\
February, 2011 & $1,411.00$ & 1378.45 & 2.31 \\
March, 2011 & $1,439.00$ & 1427.37 & 0.81 \\
April, 2011 2011 & $1,535.50$ & 1474.11 & 4.00 \\
May, 2011 & $1,536.50$ & 1518.93 & 1.14 \\
June, 2011 & $1,505.50$ & 1565.05 & 3.96 \\
\hline
\end{tabular}

\section{Limitation and Future Study}

Although system dynamics model is shown to be a valid forecasting approach as discussed in the previous section, updating of data input approximately every three months is somewhat necessary. Without continually trace on chaos factor, the percentage error of gold price forecasting from January 2010 to June 2011 is nearly $9 \%$ in average with the maximum of $18 \%$ error around the last three months. Therefore, to effectively utilize our forecasting approach and maintain a low level of error term, the analyst shall follow closely to the world's economics and political issues. This might be easier said than done because to trigger the chaos factor is relied entirely on the analyst's decision and past experience. The same limitation is also present when making decision on taken off this qualitative factor from the model.

At the same time, limitation on forecasting by monthly time period is also a drawback on gold investors or gold users in today's world market. Nowadays, gold watchers at all levels have ability to leap in and out from the market in daily basis. Gold market has changed dramatically from physical investment mode of holding and storing gold bar or jewellery to things like mutual funds, gold futures, gold certificates, and so on. Capability to forecast in shorter time period means faster response to fluctuation of the gold price. However, this limitation is not the result of system dynamic approach but rather the constraint of actual input data that sometime available monthly. Assuming having access to higher frequency raw input data, the authors recommend extending study to another important element of system dynamics namely time delays. When forecasting data at more frequent period, the happening of trigger point such as chaos and war events might not impact gold price as fast and some time delay could exist as a consequent. 
Lastly, as we all know, gold price is not affected from only U.S. and European countries' economics but also from all other major countries such as the BRIC (i.e., Brazil, Russia, China, and India). The authors have well recognized this fact but due to constraint in language translation as well as accessibility to those countries' economics data, the studied model have not yet included data from such nations. We strongly believe that taking into account all major countries concurrently will result in even more accurate model. Particularly with the fact that China's economy has roared over the last 10 years and correlation between China's CPI and gold prices over this period is shown to be higher than that with the U.S. CPI [14]. Also, as this study is the first exercise of system dynamics applied to the field of forecasting, there is possibility to utilize the same approach toward prediction of other interests than gold (e.g., rubber price, rice price, and other precious metals' prices).

\section{References}

[1] E. F. Wolstenholme, "Qualitative v. quantitative modelling: The evolving balance," J Oper Res Soc, vol. 50, no. 4, pp. 422-428, 1999.

[2] J. W. Forrester, and L. A. Martin, "Beginner exercises," MIT System Dynamics in Education Project, MIT, Cambridge, MA, Technical Report, 1997.

[3] S. G. Bantz, and M. L. Deaton, "Understanding U.S. biodiesel industry growth using system dynamics," in IEEE Systems and Information Engineering Design Symposium, Charlottesville, VA, pp. 156-161, 2006.

[4] S. Albin, "Building a system dynamics model part 1: Conceptualization," MIT System Dynamics in Education Project, MIT, Cambridge, MA, Technical Report, 1997.

[5] System Dynamics Group, "Guided study program in system dynamics," MIT, Cambridge, MA, Technical Report, 1998.

[6] L. A. Sjaastad, and F. Scacciavillani, "The price of gold and the exchange rate," J Int Money Financ, vol. 15, no. 6, pp. 879-897, 1996.

[7] M. Feldstein, "The effects of inflation on the prices of land and gold," J Public Econ, pp. 309-317, 1981.

[8] P. Vannasetta, and W. Tharmmaphornphilas, "Oil price using system dynamics," in Proceedings of the $2^{\text {nd }}$ International Conference on Business and Economics, Lhasa, Tibet, 2011.

[9] J. H. Davis, and R.. A. Aliaga-Diaz, "Oil, the economy, and the stock market [online]," 2008. Available http://ssrn.com/abstract=1136524 or http://dx.doi.org/10.2139/ssrn.1136524

[10] R. Pirog, “Oil industry profit review 2005," CRS, Washington DC, Order Code RL33373, 2006.

[11] Thailand Securities Institute, in Economics 2nd ed., Bangkok, Thailand: The Stock Exchange of Thailand, 2005.

[12] T. Tanawut, and T. Keetashewa, "Forecasting system of gold bar price (in Thai)." Bachelor Thesis, Department of Computer Science, HCU, BKK, 2007.

[13] A. Mongkolkaset, "Analysis of influencing factors on gold price (in Thai)." Master Thesis, Department of "Business Economics, UTCC, BKK, 2008.

[14] R. Cullen, "Do gold prices correlate with U.S. inflation? [online]" 2011. Available http://pragcap.com/do-gold-prices-correlate-with-u-s-inflation. 
